\title{
Role of heparan sulphate proteoglycans as potential receptors for non-piliated Pseudomonas aeruginosa adherence to non-polarised airway epithelial cells
}

\author{
MARIA C. PLOTKOWSKI, ANGELA O. COSTA, VERÔNICA MORANDI*, HELENE S. BARBOSA†, \\ HELENA B. NADER $;$, SOPHIE DE BENTZMANN§ and EDITH PUCHELLE§
}

Department of Microbiology and Immunology, and*Department of Cell Biology and Genetics, Universidade do Estado do Rio de Janeiro UERJ, †Department of Ultrastructure and Cell Biology, FIOCRUZ, Rio de Janeiro, $\ddagger$ Departament of Biochemistry, Escola Paulista de Medicina, São Paulo, Brazil and $\ddagger$ U 514 INSERM, IFR 53 Reims, France

\begin{abstract}
Tight junctions seal polarised surface epithelial respiratory cells so as to prevent the passage of bacteria and toxins through the epithelial sheet. Disruption of tight junctions, which may occur during injury and repair processes of airway epithelium, favours potential bacterial interaction with receptors from cell basolateral membranes. Earlier studies reported that non-polarised and untight epithelial respiratory cells are highly susceptible to Pseudomonas aeruginosa adherence and internalisation. As heparan sulphate proteoglycans (HSP) from cell basolateral membranes in epithelial cells without tight junctions may become accessible to bacterial ligands, the present study investigated their role as potential receptors for non-piliate $P$. aeruginosa ligands. Treatment of cells with heparitinase I and II significantly reduced $(51.2 \%$ and $51.7 \%$, respectively) $P$. aeruginosa adherence to epithelial respiratory cells without tight junctions. The internalisation of bacteria was not affected by treatment with heparitinases. Treatment of the bacteria with heparin and heparan sulphate also significantly reduced their adherence to respiratory cells $(34.3 \%$ and $43.7 \%$, respectively). Treatment of cells with other enzymes (trypsin, lipase and chondroitinase $\mathrm{ABC}$ ) or treatment of bacteria with chondroitin-4-sulphate did not modify the adherence to respiratory cells significantly. Both affinity chromatography and Western blotting assays showed the interaction of different $P$. aeruginosa outer-membrane proteins (OMPs) with heparin. Several bacterial strains showed differences in their profile of heparin-binding OMPs, but all exhibited low mol. wt $(<30 \mathrm{kDa})$ reactive proteins. Reactivity of whole bacterial cells with heparin was also observed by transmission electron microscopy. These results suggest that HSP are potential receptors for $P$. aeruginosa adherence to non-polarised and untight epithelial respiratory cells.
\end{abstract}

\section{Introduction}

Pseudomonas aeruginosa is a major respiratory pathogen in cystic fibrosis and critically ill hospitalised patients. Several in-vitro and ex-vivo studies have shown that these bacteria bind avidly to injured respiratory epithelia, whereas they adhere poorly to functional and intact epithelial respiratory cells [1-4].

Received 3 April 2000; revised version received 30 June 2000; accepted 10 July 2000.

Corresponding author: Dr M.C. Plotkowski (e-mail mcplot@ uerj.br).
In normal epithelia, junctional complexes between adjacent cells provide high resistance intercellular seals, forming a barrier between apical and basolateral domains of cell membranes. By isolating receptors from cell basolateral membranes, junctional complexes also restrict the repertoire of potential interactions which may occur between luminal bacteria and the epithelial cell surface [5]. However, in the course of traumatic, infectious or inflammatory episodes, the sealing capacity of junctional complexes can be altered significantly.

Recent studies have shown that polarised human epithelial respiratory cells presenting tight intercellular 
junctions were resistant to the adherence and internalisation of piliate $P$. aeruginosa. In contrast, high concentrations of bacteria were detected adherent to non-polarised and untight epithelial respiratory cells and also in the intracellular compartment [6]. These cells susceptible to $P$. aeruginosa infection were similar to cells found in human remodelling respiratory epithelia [7].

Proteoglycans are complex macromolecules detected on the surface of virtually all mammalian cells, consisting of a protein core with one or more covalently attached long, linear, negatively charged disaccharide repeats, termed glycosaminoglycan (GAG). Depending on the composition of the disaccharide repeat and the overall extent of sulphation, GAGs can be classified into different species, including heparin, heparan sulphate, chondroitin-4-sulphate (chondroitin sulphate A), chondroitin-6-sulphate (chondroitin sulphate C), dermatan sulphate (chondroitin sulphate B) and keratan sulphate. Heparan sulphate, the most prevalent cell surface GAG [8], consists of repeating disaccharide units composed of L-iduronic acid and $N$-acetylglucosamine residues. Heparan sulphate has been suggested as a cell receptor for a growing list of pathogenic micro-organisms, including viruses, bacteria and protozoa, as reviewed by Rostand and Esko [9].

In polarised epithelial cells, heparan sulphate proteoglycans (HSP) are sequestered at cell basolateral surfaces where they co-localise with actin filament bundles and contribute to cell binding to the basement membrane $[8,10]$. However, in untight epithelia, proteoglycans can be detected surrounding epithelial cells [10].

Bacterial adherence to host tissues probably results from the additive interaction between different bacterial surface ligands and specific mucosal receptors. Pilin, the first bacterial gene product implicated in $P$. aeruginosa adherence to epithelial respiratory cells $[11,12]$, recognises the GalNAc $\beta 1-4$ Gal moiety of asialoGM1 glycolipids [13]. Although asialoGM1 residues are infrequent in normal respiratory epithelia, they are increased in respiratory cells from cystic fibrosis patients $[14,15]$ and in non-polarised untight regenerating respiratory cells [16]. P. aeruginosa also expresses non-pilus ligand(s) with affinity for respiratory mucins $[17,18]$ and epithelial respiratory cells $[19,20]$. However, the nature of the complementary molecules on the host cell surface that bind these non-pilus ligands has not been clearly established.

This study analysed the contribution of non-pilus adhesins in $P$. aeruginosa adherence to and internalisation by non-polarised untight epithelial respiratory cells and also determined the role of cell surface proteoglycans as receptors for non-pilus $P$. aeruginosa ligands.

\section{Materials and methods}

\section{Airway epithelial cell culture}

Transformed human bronchial epithelial cell line 16 HBE14o- [21], kindly provided by $\mathrm{Dr}$ Gruenert (University of California, USA), was cultured at $37^{\circ} \mathrm{C}$ in M-199-HEPES medium (Gibco BRL, Grand Island, NY, USA) containing fetal calf serum $10 \%$ and antibiotics until confluency in uncoated 24-well microtitration plates. It has been shown that whereas 16 HBE14o- cells cultured on thick collagen gels or on porous membranes are differentiated, polarised and tight, cells cultured on rigid supports are non-polarised and untight, as they express $\beta 1$ integrins at their apical membranes, do not exclude lanthanum nitrate and do not express ZO-1 protein [6].

\section{Bacteria}

Non-mucoid piliate strain PAK and the pilin-minus isogenic $\mathrm{PAK} / \mathrm{p}^{-}$strain, constructed by gene replacement, were kindly provided by Dr Paranchych (University of Alberta, Canada). Non-mucoid piliate strain PAO1 was kindly provided by Dr Vasil (University of Colorado, USA). Non-mucoid $P$. aeruginosa strains 1440 and 1412 were fresh isolates from sputum of cystic fibrosis patients, strain 572 was a fresh isolate from blood, and strains 568 and 581 were fresh isolates from stools from asymptomatic patients. All clinical isolates were non-mucoid, oxidised glucose in O-F carbohydrate base, were oxidase positive, produced pyocyanin and pyoverdin and were able to grow at $42^{\circ} \mathrm{C}$. Bacteria were grown overnight at $37^{\circ} \mathrm{C}$ in Trypticase Soy Broth (TSB; Difco Laboratories, Detroit, MI, USA), harvested by centrifugation and resuspended in $\mathrm{M}-199$ medium to $\mathrm{A}_{640}=0.1$, corresponding to $10^{8} \mathrm{cfu} / \mathrm{ml}$. Bacterial concentration was confirmed by quantitative culture on Trypticase Soy Agar (TSA; Difco).

\section{Interaction of piliate and non-piliate $P$. aeruginosa with respiratory cells}

Confluent cell cultures were exposed to $500 \mu \mathrm{l}$ of PAK and $\mathrm{PAK} / \mathrm{p}^{-} P$. aeruginosa suspensions containing $10^{8} \mathrm{cfu} / \mathrm{ml}$. After $1 \mathrm{~h}$ at $37^{\circ} \mathrm{C}$, supernates were removed and some culture wells were rinsed four times with mild agitation and incubated with gentamicin $300 \mu \mathrm{g} / \mathrm{ml}$ in M-199 medium for $1 \mathrm{~h}$ to kill extracellular bacteria. In parallel, other infected culture wells were incubated with antibiotic-free culture medium for $1 \mathrm{~h}$. Then, cells from at least three different antibiotic-treated or untreated wells were washed four times and lysed with sterile PBS containing Triton X-100 (Sigma) 0.1\%. Samples of lysates from cells treated with gentamicin and from cells treated with the antibiotic-free medium were serially diluted and plated on TSA, to quantify viable intracellular bacteria and total - intracellular (IC) plus extracellular (EC) - bacteria associated with 
respiratory cells, respectively. The efficacy of gentamicin in killing extracellular bacteria was systematically analysed by plating on TSA the antibiotic-containing medium which had been kept in contact with the $P$. aeruginosa-infected cell cultures for $1 \mathrm{~h}$.

\section{Inhibitory assays}

Before incubation with $P$. aeruginosa suspensions in the bacterial interaction assays, confluent cell cultures were treated with the following enzymes: lipase (Sigma) $100000 \mathrm{U} / \mathrm{ml}$ in $0.01 \mathrm{M}$ phosphate-buffered saline (PBS), $\mathrm{pH} 7.2$, for $1 \mathrm{~h}$; trypsin (Difco) $50 \mu \mathrm{g} / \mathrm{ml}$ in PBS for $30 \mathrm{~min}$; chondroitinase $\mathrm{ABC}$, heparitinase I and heparitinase II $1 \mathrm{U} / \mathrm{ml}$ in ethylene-diamine acetate buffer, $\mathrm{pH} 7.0$, for $2 \mathrm{~h}$. Chondroitinase ABC from Proteus vulgaris and heparitinases I and II from Flavobacterium heparinum were purified as described previously [22]. Heparitinase I degrades the glucuronic acid region of heparan sulphate to $4.5-\mathrm{kDa} 6-\mathrm{O}-$ sulphated oligosaccharides containing iduronic acid, whereas heparitinase II degrades the iduronic acid and 6-O-sulphated glucosamine to oligosaccharides composed of glucuronic acid and N-acetylated and $\mathrm{N}$ sulphated glucosamine [23]. After enzymic treatment at $37^{\circ} \mathrm{C}$, cells were rinsed once with PBS, incubated with $\mathrm{PAK} / \mathrm{p}^{-}$P. aeruginosa suspension for $1 \mathrm{~h}$, rinsed four times with mild agitation, incubated with antibiotic-free culture medium or with gentamicin-containing medium for $1 \mathrm{~h}$, rinsed and lysed, as described previously. In other assays, bacteria were treated with chondroitin-4sulphate (Sigma), heparan-4-sulphate (Sigma) or heparin (Sigma) $250 \mu \mathrm{g} / \mathrm{ml}$ for $1 \mathrm{~h}$, washed once with PBS and incubated with respiratory cells. To ascertain the role of GAG charge in inhibition of adherence of $\mathrm{PAK} / \mathrm{p}^{-} P$. aeruginosa to respiratory cells, bacteria were also treated with dextran sulphate (Sigma; average $\left.\mathrm{M}_{\mathrm{r}} 8000 \mathrm{Da}\right)$ and dextran $250 \mu \mathrm{g} / \mathrm{ml}$ before incubation with respiratory cells. The degree of inhibition in each assay was calculated as $\left(\mathrm{A}_{\max }-\mathrm{A}_{\mathrm{inh}}\right) / \mathrm{A}_{\max } \times 100$, where $A_{\max }$ was the association in the absence of inhibitor and $A_{\text {inh }}$ was the association in the presence of the inhibitor.

\section{Bacterial cell-wall extract}

P. aeruginosa $\mathrm{PAK} / \mathrm{p}^{-}$outer-membrane proteins (OMP) were extracted as described by Carnoy et al. [17]. Briefly, bacteria grown in TSB overnight at $37^{\circ} \mathrm{C}$ were washed twice with PBS and suspended in $50 \mathrm{mM}$ sodium citrate solution ( $\mathrm{pH}$ 7.4) containing Zwittergent 3-14 (Calbiochem, San Diego, CA, USA) 0.1\% w/v, $1 \mathrm{mM}$ phenylmethylsulphonyl fluoride (Sigma) and $10 \mathrm{~mm}$ EDTA (Sigma). After incubation at $45^{\circ} \mathrm{C}$ for $25 \mathrm{~min}$, bacteria were pelleted by centrifugation at $15400 \mathrm{~g}$ for $30 \mathrm{~min}$ at $4^{\circ} \mathrm{C}$. Supernates containing the extracted proteins were dialysed overnight against distilled water containing sodium azide $0.02 \% \mathrm{w} / \mathrm{v}$ and lyophilised.

\section{Interaction of bacterial OMPs with heparin}

Because there are similarities between heparin and heparan sulphate in structure $[23,24]$ and binding properties [8], biotinylated heparin was used to investigate, by Western blotting assays, whether nonpilus ligands with affinity for heparan sulphate are proteins from the outer membranes of bacterial cells. $P$. aeruginosa $\mathrm{PAK} / \mathrm{p}^{-}$OMP extract, as well as proteins from a $10-\mathrm{kDa}$ protein ladder calibration kit (Gibco BRL), were analysed by SDS-PAGE with a Minigel system (Mini Protean II; BioRad Laboratories, Richmond, CA, USA) under non-reducing conditions. After electrophoresis, proteins were electrotransferred to nitrocellulose sheets (Immobilon N; Millipore Corporation, Bedford, MA, USA). For the detection of heparin binding to bacterial OMPs, nitrocellulose replicas were incubated overnight at $4^{\circ} \mathrm{C}$ in PBS containing Tween $200.5 \%$ and bovine serum albumin 1\% (PBS-T-BSA) and then incubated with biotinylated heparin (Sigma) $2 \mu \mathrm{g} / \mathrm{ml}$ in PBS-T-BSA for $1 \mathrm{~h}$ at room temperature. The blots were washed four times for 5 min each with PBS-T with mild agitation and exposed to streptavidinperoxidase complex (Amersham, Arlington Heights, IL, USA) diluted 1 in 5000 in PBS-T-BSA for $30 \mathrm{~min}$. Binding of heparin to bacterial OMPs was detected by developing the reactive bands with a solution containing imidazole (Sigma), hydrogen peroxide and 3,3 diaminobenzidine (Sigma) 0.1\%.

\section{Characterisation of the heparin-reactive $P$. aeruginosa $P A K / p^{-}$OMPS}

Bacterial OMPs binding to heparin were partially characterised by affinity chromatography with a column containing $1 \mathrm{ml}$ of heparin sepharose gel (Hi-Trap; Pharmacia Biotech, Uppsala, Sweden) as the affinity matrix. Lyophilised OMPs $(1 \mathrm{mg})$ were suspended in distilled water and applied to the column equilibrated with $15 \mathrm{mM}$ Tris buffer, pH 7.6, containing $150 \mathrm{mmM}$ $\mathrm{NaCl}$ and $2 \mathrm{mM} \mathrm{CaCl}_{2}$. Non-specifically bound material was eluted with Tris- $150 \mathrm{mM} \mathrm{NaCl}$ buffer. Bound proteins were then eluted sequentially with Tris buffer containing $300 \mathrm{~mm}, 550 \mathrm{~mm}, 1 \mathrm{M}$ and $2 \mathrm{M} \mathrm{NaCI}$. Eluted samples were dialysed against distilled water and concentrated with a Speed Vac Plus system (Savant Instruments, Holbrook, NY, USA) before SDS-PAGE analysis.

\section{Electron microscopy}

The surface expression of heparin-binding OMPs in non-piliate $P$. aeruginosa was investigated by transmission electron microscopy (TEM). Bacteria were cultured in TSB overnight at $37^{\circ} \mathrm{C}$. Then $1 \mu \mathrm{l}$ of the bacterial culture was placed on collodion-coated nickel grids and dried. Grids were floated on to a droplet of PBS containing BSA 1\% (PBS-BSA) for $5 \mathrm{~min}$ and transferred on to a droplet of biotinylated heparin at $20 \mu \mathrm{g} / \mathrm{ml}$ in PBS-BSA. After $1 \mathrm{~h}$ at room temperature, grids were rinsed by three successive transfers on to 
PBS and floated on to a streptavidin-colloidal gold complex (Amersham) diluted 1 in 4 in PBS-BSA for $30 \mathrm{~min}$. After rinsing with distilled water, grids were examined with a 906 Zeiss transmission electron micrsocope. The specificity of the labelling was tested by omitting the biotinylated heparin.

\section{Statistical analysis}

Student's $t$ test was used to assess the significance of differences between means in binding assays; a $p$ value $<0.05$ was considered significant.

\section{Results}

Contribution of non-pilus ligands to adherence of $P$. aeruginosa to and internalisation by untight $16 \mathrm{HBE} 14 \mathrm{o}^{-}$cells

The role of non-pilus ligands in the interaction of $P$. aeruginosa with untight cells was assessed by comparing the piliate parental PAK strain with the piluslacking isogenic $\mathrm{PAK} / \mathrm{p}^{-}$strain. The concentration of total PAK $/ \mathrm{p}^{-}$bacteria associated with untight epithelial cell cultures (intracellular plus extracellular; 7.3SD2.2 $\left.\times 10^{5} \mathrm{cfu} / \mathrm{ml}\right)$ was significantly lower $(\mathrm{p}<0.01)$ than the concentration of total piliate PAK bacteria $\left(4.1 \mathrm{SD} 3.2 \times 10^{7} \mathrm{cfu} / \mathrm{ml}\right)$. The concentration of nonpiliate $P$. aeruginosa in the intracellular compartment of untight cells $\left(3.8 \mathrm{SD} 1.5 \times 10^{4} \mathrm{cfu} / \mathrm{ml}\right)$ was also significantly lower $(p<0.05)$ than the concentration of the piliate strain $\left(1.0 \mathrm{SD} 0.4 \times 10^{5} \mathrm{cfu} / \mathrm{ml}\right)$ (Fig. 1a). As intracellular bacteria constitute a minor fraction of the total bacteria associated with respiratory cells, it is assumed, for the sake of simplificity, that total bacteria would correspond to the extracellular adherent microorganisms. The results presented above demonstrate that (i) although pili conferred significant advantages to $P$. aeruginosa in its ability to adhere, non-pilus ligands also contributed substantially to bacterial adherence to untight respiratory cells; (ii) the contribution of pili to $P$. aeruginosa internalisation was less important than to adherence, as the concentration of PAK strain in the intracellular compartment of untight cells was only 2.5 times higher than the concentration of $\mathrm{PAK} / \mathrm{p}^{-}$ strain. The adherence of $P$. aeruginosa $\mathrm{PAK} / \mathrm{p}^{--}$to untight respiratory cells was confirmed by scanning electron microscopy of cells exposed to bacterial suspension for $1 \mathrm{~h}$ and rinsed four times with mild agitation before being processed for analysis (Fig. 1b).

\section{HSP as cell receptors for non-piliate $P$. aeruginosa}

To characterise the nature of receptors available on untight respiratory cells for non-pilus $P$. aeruginosa ligands, cell cultures were treated with different enzymes before incubation with $P$. aeruginosa $\mathrm{PAK} / \mathrm{p}^{-}$ suspensions. Treatment of cells with lipase, trypsin or chondroitinase $\mathrm{ABC}$ did not modify the adherence of $P$. aeruginosa to untight epithelial respiratory cells. In contrast, bacterial adherence was significantly inhibited $(\mathrm{p}<0.01)$ by treatment of cells with heparitinase I and II, (51.2\% and $51.7 \%$ respectively) (Fig. 2a). Internalisation of bacteria by untight cells was not affected by any enzyme. To further analyse the role of HSP as receptors for non-piliate $P$. aeruginosa, bacteria were treated with different GAGs before incubation with cell cultures. Treatment of $P$. aeruginosa with heparin, heparan sulphate or chondroitin-4-sulphate did not modify bacterial internalisation by respiratory cells (Fig. 3a). In contrast, treatment with heparin and heparan sulphate diminished significantly $(\mathrm{p}<0.05)$ bacterial adherence to respiratory cells $(31.3 \%$ and $38.9 \%$, respectively) (Fig. 3b). Although treatment with chondroitin-4-sulphate reduced bacterial adherence by $29.6 \%$, the concentration of treated bacteria adherent to respiratory cells was not significantly different $(\mathrm{p}=0.052)$ from the concentration of control microorganisms.
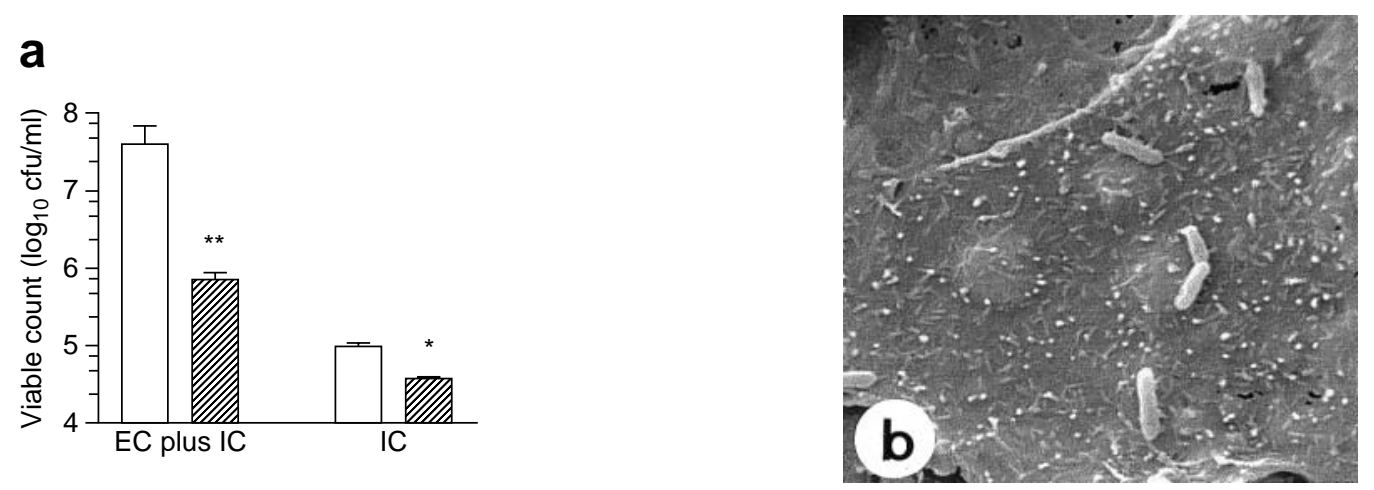

Fig. 1.(a) Concentration of total (IC + EC) bacteria associated with untight epithelial respiratory cells and of IC piliate PAK $(\square)$ and non-piliate PAK $/ \mathrm{p}^{-}(\mathbb{Q})$ strains of P. aeruginosa. Data represent means and SD obtained in three different assays performed in triplicate. ${ }^{*} \mathrm{p}<0.05$ and ${ }^{* *} \mathrm{p}<0.01$ versus PAK. (b) Scanning electron micrograph of $P$. aeruginosa $\mathrm{PAK} / \mathrm{p}^{-}$adherent to untight epithelial respiratory cells. Cells cultured on $13-\mathrm{mm}$ glass coverslips were incubated with $0.5 \times 10^{7}$ bacteria for $1 \mathrm{~h}$, rinsed four times with PBS, fixed in glutaraldehyde $2.5 \%$, post-fixed in osmium tetroxide $1 \%$, dehydrated through graded concentrations of ethanol, critical-point dried with $\mathrm{CO}_{2}$ and coated with gold palladium. 
Role of charge in GAG inhibition of adherence of non-piliate P. aeruginosa to respiratory cells

Because interactions of GAGs with their ligands are mediated, at least in part, by ionic interactions [25], the role of GAG charge in the inhibition of adherence of $P$. aeruginosa $\mathrm{PAK} / \mathrm{p}^{-}$to untight respiratory cells was assessed with dextran sulphate, a polyanionic synthetic carbohydrate with similar charge density and molecular mass to heparin. Dextran sulphate inhibited the adherence of PAK $/ \mathrm{p}^{-}$to $20 \%$ of cells. The concentration of adherent treated bacteria was significantly lower than the concentration of control untreated bacteria $(p<0.05)$. In contrast, treatment of bacteria with

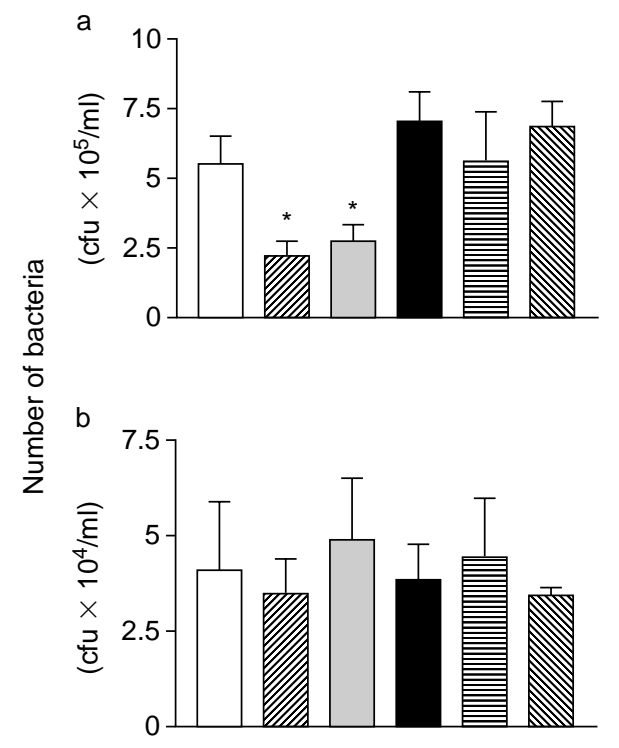

Fig. 2. Effect of different enzymes on the interaction of $P$. aeruginosa $\mathrm{PAK} / \mathrm{p}^{-}$with untight respiratory cells. (a) Concentration of total bacteria (IC + EC) associated with control untreated cells and with cells treated with different enzymes. (b) Percentage of IC bacteria in control cells and in cells treated with different enzymes. Data are means and SEM obtained in three different assays performed in quadruplicate. ${ }^{*} \mathrm{p}<0.01$ when data were compared with bacterial concentration in control untreated culture. $\square$, Control; $\square$, heparitinase I; $\square$,

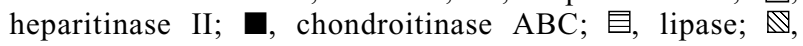
trypsin. dextran of similar mass, used as a 'mass control', had no effect on the concentration of adherent microorganisms (Fig. 3c).

\section{Electron microscopy}

Electron microscopy confirmed the affinity of nonpiliate $P$. aeruginosa for HSP. By TEM, the outer surface of bacteria exposed to biotinylated heparin and to streptavidin-colloidal gold complex was seen to be uniformly labelled with gold granules (Fig. 4a). No labelling was seen in controls in which biotinylated heparin was omitted (Fig. 4b).

\section{Characterisation of non-piliate P. aeruginosa ligands for heparin}

The role of OMPs as potential ligands for heparan sulphate proteoglycans was first investigated by SDSPAGE and Western blotting. Fig. 5a shows the SDSPAGE profile of total P. aeruginosa OMPs stained with Coomassie Blue, whereas Fig. 5b shows the reactivity of the OMPs separated in a polyacrylamide $15 \%$ gel with biotinylated heparin. Two reactive proteins of

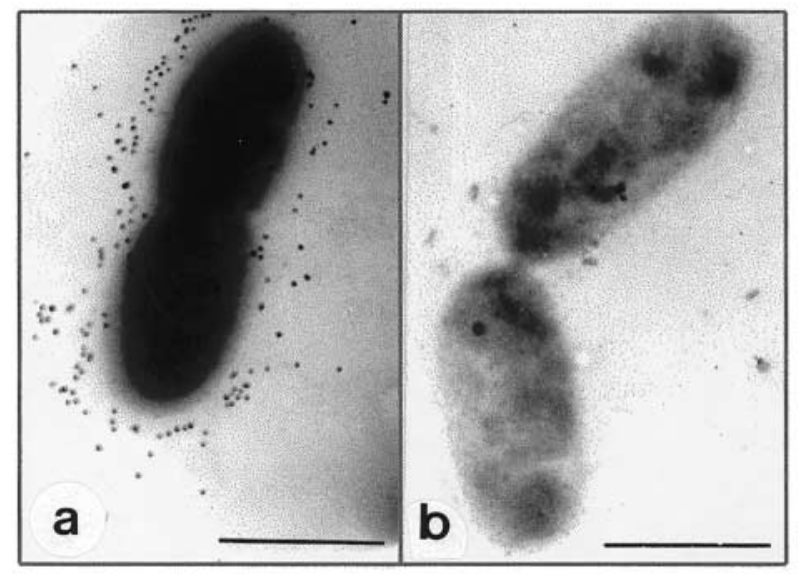

Fig. 4. Transmission electron micrograph of non-piliate $P$. aeruginosa treated with (a) biotinylated heparin and streptavidin-colloidal gold complex and (b) biotin $1 \mathrm{mg} / \mathrm{ml}$ and streptavidin-colloidal gold complex. Bars = $1 \mu \mathrm{m}$.
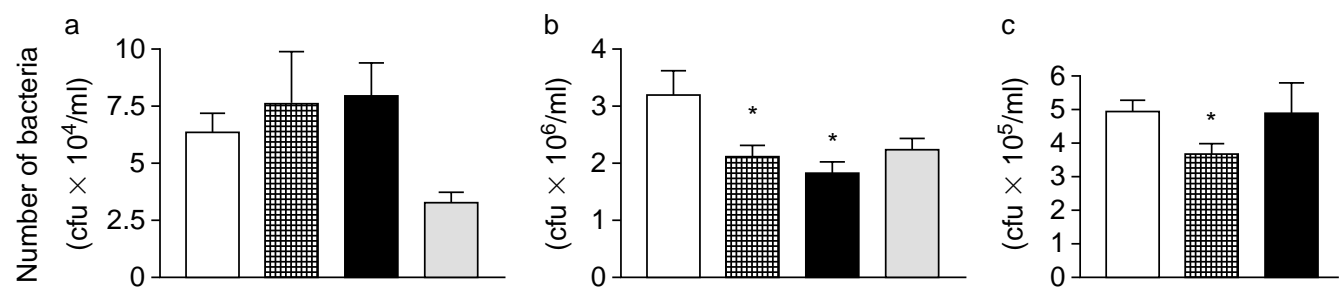

Fig. 3. Inhibition of the adherence of non-piliate $P$. aeruginosa to untight respiratory cells. (a) Concentration of IC control bacteria and of bacteria treated with different GAGs before incubation with respiratory cells. (b) and (c) Concentration of total associated control bacteria and of bacteria treated with different sugars at $250 \mu \mathrm{g} / \mathrm{ml} \mathrm{before}$ incubation with respiratory cells. Data are means and SEM obtained in three different assays performed in triplicate. ${ }^{*} \mathrm{p}<0.05$ when treated cells were compared with controls. (b) $\square$, control; 曲, heparin; $\mathbf{\square}$, heparan sulphate; $\square$, chrondroitin 4-sulphate. (c) $\square$, control; 曲, dextran sulphate; $\mathbf{\square}$, dextran. 
a

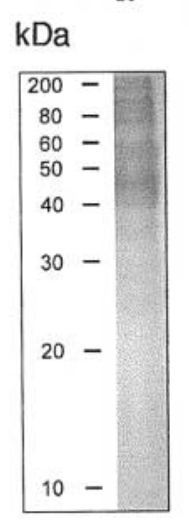

b

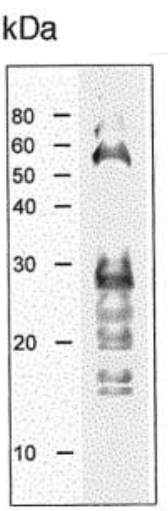

c

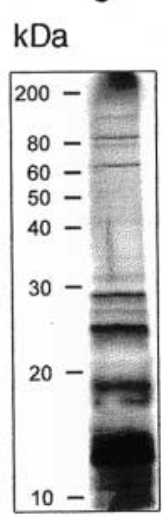

Fig. 5. Identification of $P$. aeruginosa heparin-binding OMPs. (a) PAK $/ \mathrm{p}^{-}$OMPs separated in a $15.0 \%$ gel and stained with Coomassie Blue. (b) PAK $/ \mathrm{p}^{-}$OMPs blotted on to nitrocellulose and probed with biotinylated heparin $2 \mu \mathrm{g} / \mathrm{ml}$. (c) Silver staining of PAK $/ \mathrm{p}^{-}$OMPs eluted from a Hi-Trap Heparin-Sepharose column with $55 \mathrm{mM} \mathrm{NaCl}$. Numbers at left of each panel refer to the molecular masses of protein standards in $\mathrm{kDa}$.

mol. wt $>50 \mathrm{kDa}$ and also several low mol. wt proteins $(<30 \mathrm{kDa})$ are present. No band appeared when nitrocellulose membranes were incubated with streptavidin-peroxidase complex alone (data not shown). To further characterise the role of $P$. aeruginosa OMPs as ligands for HSP, bacterial extracts were submitted to affinity chromatography in a heparin sepharose gel column and eluted samples were analysed by SDSPAGE. Most OMPs were eluted with $550 \mathrm{mM} \mathrm{NaCl}$. Fig. 5c shows the profile of the sample eluted with $500 \mathrm{mM}, \mathrm{NaCI}$ after silver staining.

\section{Reactivity of different P. aeruginosa strains with heparin}

Fig. 6 shows the reactivity with biotinylated heparin of OMPs from piliate $P$. aeruginosa strains PAK and PAO1 as well as from five clinical isolates. These strains differed in their heparin-reactive OMP profiles. Proteins with mol.wts $>50 \mathrm{kDa}$ were detected in strains PAK, PAO-1, 572 and 1412 but not in the others. However, all strains presented the low mol. wt reactive proteins.

\section{Discussion}

Most studies aimed at the identification of bacterial adhesins and of cell receptors participating in the association of $P$. aeruginosa with respiratory cells have focused on piliate bacteria. However, Saiman et al. [26] have shown that even with high titre antibodies raised against homologous pilin, adherence of $P$. aeruginosa to respiratory cells could be reduced by no more than $50 \%$, suggesting an important role for non-pilus adhesins. The present study reports evidence for the role of ligands distinct from polar pili in the

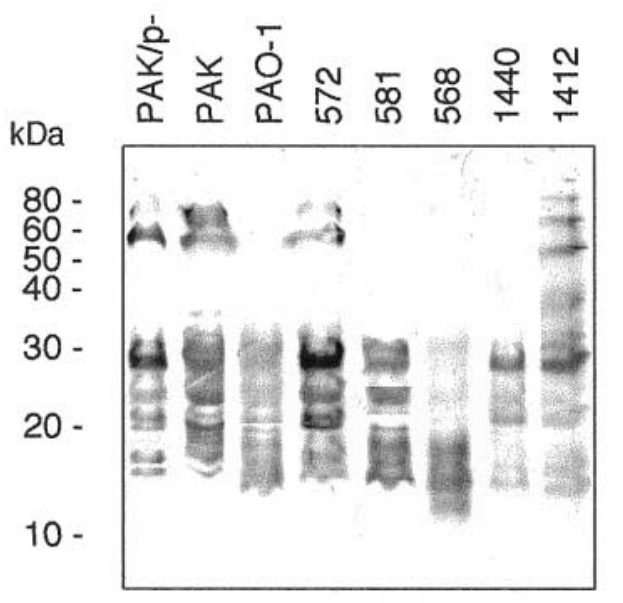

Fig. 6. Western blotting analysis of the affinity of OMPs from different $P$. aeruginosa strains for biotinylated heparin. OMPs were separated in a $15 \%$ gel, blotted on to nitrocellulose and incubated with biotinylated heparin at $2 \mu \mathrm{g} / \mathrm{ml}$. Numbers on the left refer to the molecular masses of protein standards in $\mathrm{kDa}$.

association of $P$. aeruginosa with untight epithelial respiratory cells. This conclusion was based on the observation that a genetically engineered bacterial mutant in which the pilin structural gene was inactivated retained part of the cell-binding activity of the parental strain. A mechanism for adherence of $P$. aeruginosa to untight respiratory cells which depends on the recognition of HSP on host cells by proteins from the bacterial outer membranes was identified and partially characterised. The partial inhibition of adherence by pretreatment of cells with heparitinase I and II, the electron microscopic demonstration that heparin binds to the outer surface of bacterial cells and the fact that bacteria express several OMPs that bind specifically to heparin demonstrate that HSP represent receptors for adherence of non-piliate $P$. aeruginosa to epithelial respiratory cells. $P$. aeruginosa OMPs have already been identified as adhesins recognising human respiratory mucins [17,27], laminin [28] and $\alpha 5 \beta 1$ integrins from respiratory epithelial cells [20]. Although the non-mucoid $P$. aeruginosa strains included in this study differed in their heparin-binding OMP profiles, all exhibited reactive proteins of mol. wt $<30 \mathrm{kDa}$. Interestingly, $P$. aeruginosa OMPs were shown to present sequence homology with the calcium-binding repeats of thrombospondin [29], an extracellular matrix protein to which cell surface heparan sulphate proteoglycans bind avidly $[8,10]$. These low mol. wt heparin-reactive proteins may represent part of a unique protein modified by boiling OMP extracts in SDS solution, before SDS-PAGE analysis. However, as TEM demonstrated with labelling of the whole bacterial cell with heparin-colloidal gold, at least some epitopes of this protein are likely to be located on the surface of bacterial cells.

Cell surface proteoglycans contain one or more type of GAG chain; e.g., syndecan contains three or four 
heparan sulphate and one or two chondroitin sulphate chains distributed on its extracellular domain [8, 25]. Adherence of $P$. aeruginosa $\mathrm{PAK} / \mathrm{p}^{-}$to untight respiratory cells was inhibited in $31.3 \%$ and $38.4 \%$ of cells, with heparin and heparan sulphate, respectively and in $29.6 \%$ with chondroitin sulphate. Accordingly, the possibility cannot be ruled out that besides heparan sulphate, the cell surface proteoglycan accounting for adherence of $P$. aeruginosa $\mathrm{PAK} / \mathrm{p}^{-}$may contain additional GAG molecules that also participate in bacterial adherence. Alternatively, the same bacterial ligand may recognise different classes of proteoglycans, as described previously [30], or the binding of chondroitin sulphate to the surface of bacteria may have inhibited their attachment to respiratory cell surface HSP by steric hindrance or by conferring a strong negative charge to the bacterial surface.

Interactions of proteoglycans with ligands are predominantly ionic and are mainly related to the charge density on the GAG $[25,31]$. The most sulphated GAG (e.g., heparin) is generally considered to be the most reactive. To assess the specificity of GAG interaction with $P$. aeruginosa, bacteria were treated with highly charged polyanionic dextran sulphate before incubation with respiratory cells. Dextran sulphate significantly inhibited bacterial interaction with respiratory cells to $20.0 \%$. The inhibition of $P$. aeruginosa binding to cells by dextran sulphate supports a role for charge in the OMP-dependent interaction of bacteria with cells. The contribution of charge to the inhibitory effect of dextran sulphate was confirmed by experiments done with dextran alone. However, as stated before [31], it is not uncommon for GAG-binding ligands to recognise multiple species of GAGs because the polyanionic nature of these molecules is a critical determinant in these interactions. Moreover, dextran sulphate has already been shown to inhibit the proteoglycandependent adherence of other bacteria [30, 32, 33]. Accordingly, adherence of $P$. aeruginosa to untight respiratory cells is likely to be influenced by a variety of factors, including the specificity and the degree of sulphation of the carbohydrate moieties contained in the cellular proteoglycans.

P. aeruginosa is a major respiratory pathogen in cystic fibrosis patients. As a consequence of abnormal CFTR function [34], glycoconjugates from these patients' epithelial cells present increased sulphation. Accordingly, it can be speculated as to whether the role of charge density in the interaction between $P$. aeruginosa ligands and host cell receptors in the airways of these patients may be pathologically enhanced. Interestingly, recent studies have proposed dextran and dextran sulphate as anti-adhesive therapy for preventing $P$. aeruginosa infections in cystic fibrosis patients [35].

Heparan sulphate-reacting OMPs have been identified in other human bacterial pathogens, such as Borrelia burgdorferi [32], Haemophilus influenzae [33], Neis- seria meningitidis [36] and N. gonorrhoeae [37,38]. As expected on the basis of the interaction of the cytoplasmic domain of proteoglycan core proteins with cytoskeleton, cell surface HSP have also been reported to participate in internalisation of bacteria such as $N$. gonorrhoeae and $N$. meningitidis by host cells [36, 38,39 ]. In contrast, in the present study no relationship could be established between interactions of OMPs with HSP and P. aeruginosa internalisation by untight epithelial respiratory cells. A likely explanation for these results is that $P$. aeruginosa-binding cell surface HSP may serve as a co-receptor and participate in the formation of a receptor complex involving multiple bacterial and cell molecules that account for bacterial entry, a situation seen with various growth factors and cytokine receptors [40].

Adherence of micro-organisms to host tissues is a critical first step in the pathogenesis of infection. The results of the present study indicate that $P$. aeruginosa OMPs bind to cell surface HSP that may be exposed at apical membranes of untight epithelial respiratory cells. HSP is also present, in high concentrations, in the extracellular matrix. The ubiquity of HSP would also contribute to the tendency of $P$. aeruginosa to infect injured tissues, in which the extracellular matrix becomes accessible to bacterial ligands. Determining whether the HSP may contribute to the colonisation of injured airway mucosa in vivo will require further study.

We thank Maria A. Pereira da Silva for excellent technical assistance and Marco A. Louzada de Freitas for help with micrographs. This work was supported by grants from AFLM (France), CNPq (Brazil)INSERM (France) and grant no. 41960881.00 from FINEP/MCT/ PRONEX (Brazil).

\section{References}

1. Plotkowski MC, Beck G, Tournier JM, Bernardo-Filho M, Marques EA, Puchelle E. Adherence of Pseudomonas aeruginosa to respiratory epithelium and the effect of leucocyte elastase. J Med Microbiol 1989; 30: 285-293.

2. Plotkowski MC, Chevillard M, Pierrot D et al. Differential adhesion of Pseudomonas aeruginosa to human respiratory epithelial cells in primary culture. J Clin Invest 1991; 87: 2018-2028.

3. Philippon S, Streckert HJ, Morgenroth K. In vitro study of the bronchial mucosa during Pseudomonas aeruginosa infection. Virchows Archiv A Pathol Anat Histopathol 1993; 423: 39-43.

4. Tsang KWT, Rutman A, Tanaka E et al. Interaction of Pseudomonas aeruginosa with human respiratory mucosa in vitro. Eur Respir J 1994; 7: 1746-1753.

5. Molitoris BA, Nelson WJ. Alterations in the establishment and maintenance of epithelial cell polarity as a basis for disease processes. J Clin Invest 1990; 85: 3-9.

6. Plotkowski MC, de Bentzmann S, Pereira SHM et al. Pseudomonas aeruginosa internalization by human epithelial respiratory cells depends on cell differentiation, polarity and junctional complex integrity. Am J Respir Cell Mol Biol 1999; 20: $880-890$

7. Herard A-L, Zahm J-M, Pierrot D, Hinnrasky J, Fuchey C, Puchelle E. Epithelial barrier integrity during in vitro wound repair of the airway epithelium. Am J Respir Cell Mol Biol 1996; 15: 624-632.

8. Bernfield M, Kokenyesi R, Kato $\mathrm{M}$ et al. Biology of the syndecans: a family of transmembrane heparan sulfate proteoglycans. Annu Rev Cell Biol 1992; 8: 365-393. 
9. Rostand KS, Esko JD. Microbial adherence to and invasion through proteoglycans. Infect Immun 1997; 65: 1-8.

10. Rapraeger A, Jalkanen M, Bernfield M. Cell surface proteoglycan associates with the cytoskeleton at the basolateral cell surface of mouse mammary epithelial cells. J Cell Biol 1986; 103: 2683-2696.

11. Ramphal R, Sadoff JC, Pyle M, Silipigni JD. Role of pili in the adherence of Pseudomonas aeruginosa to injured tracheal epithelium. Infect Immun 1984; 44: 38-40.

12. Doig P, Todd T, Sastry PA et al. Role of pili in adhesion of Pseudomonas aeruginosa to human respiratory epithelial cells. Infect Immun 1988; 56: 1641-1646.

13. Sheth HB, Lee KK, Wong WY et al. The pili of Pseudomonas aeruginosa strains PAK and PAO bind specifically to the carbohydrate sequence bGalNAc (1-4) bGal found in glycosphingolipids asialo-GM1 and asialo-GM2. Mol Microbiol 1994; 11: 715-723.

14. ImmundoL, Barasch J, Prince A, Al-Awqati Q. Cystic fibrosis epithelial cells have a receptor for pathogenic bacteria on their apical surface. Proc Natl Acad Sci USA 1995; 92: 3019-3023.

15. Saiman L, Prince A. Pseudomonas aeruginosa pili bind asialoGM1 which is increased on the surface of. cystic fibrosis epithelial cells. J Clin Invest 1993; 92: 1875-1880.

16. de Bentzmann S, Roger P, Dupuit F et al. Asialo GM1 is a receptor for Pseudomonas aeruginosa adherence to regenerating respiratory epithelial cells. Infect Immun 1996; 64: 15821588 .

17. Carnoy C, Scharfman A, van Brussel E, Lamblin G, Ramphal R, Roussel P. Pseudomonas aeruginosa outer membrane adhesins for human respiratory mucus glycoproteins. Infect Immun 1994; 62: 1896-1900.

18. Ramphal R, Koo L, Ishimoto KS, Tolten PA, Lara JC, Lory S. Adhesion of Pseudomonas aeruginosa pilin-deficient mutants to mucin. Infect Immun 1991; 59: 1307-1311.

19. Simpson DA, Ramphal R, Lory S. Genetic analysis of Pseudomonas aeruginosa adherence: distinct genetic loci control attachment to epithelial cells and mucins. Infect Immun 1992; 60: 3771-3779.

20. Roger P, Puchelle E, Bajolet-Laudinat $\mathrm{O}$ et al. Fibronectin and $\alpha 5 \beta 1$ integrin mediate binding of Pseudomonas aeruginosa to repairing airway epithelium. Eur Respir J 1999; 13: 13011309.

21. Cozens AL, Yezzi MJ, Yamaya M et al. A transformed human epithelial cell line that retains tight junctions post crisis. In Vitro Cell Dev Biol 1992; 28A: 735-744.

22. Nader HB, Porcionatto MA, Tersariol ILS et al. Purification and substrate specificty of heparitinase I and heparitinase II from Flavobacterium heparinum. J Biol Chem 1990; 265: 16807-16813.

23. Dietrich CP, Nader HB, Straus AH. Structural differences of heparan sulfates according to the tissue and species of origin. Biochem Biophys Res Commun 1983; 111: 865-871.

24. Dietrich CP, Tersariol IL, Toma L et al. Structure of heparan sulfate: identification of variable and constant oligosaccharide domains in eight heparan sulfates of different origins. Cell Mol Biol 1998; 44: 417-429.
25. Ruoslahti E. Structure and biology of proteoglycans. Annu Rev Cell Biol 1988; 4: 229-255.

26. Saiman L, Sadoff J, Prince A. Cross-reactivity of Pseudomonas aeruginosa antipilin monoclonal antibodies with heterogeneous strains of $P$. aeruginosa and Pseudomonas cepacia. Infect Immun 1989; 57: 2764-2770.

27. Reddy MS. Human tracheobronchial mucin: purification and binding to Pseudomonas aeruginosa. Infect Immun 1992; 60: $1530-1535$.

28. Plotkowski M-C, Tournier J-M, Puchelle E. Pseudomonas aeruginosa strains possess specific adhesins for laminin. Infect Immun 1996; 64: 600-605.

29. De Mot R, Vanderleyden J. A conserved surface-exposed domain in major outer membrane proteins of pathogenic Pseudomonas and Branhamella species shares sequence homology with the calcium-binding repeats of the eukaryotic extracellular matrix protein thrombospondin. Mol Microbiol 1994; 13: 379-380.

30. Leong JM, Wang H, Magoun L et al.. Different classes of proteoglycans contribute to the attachment of Borrelia burgdorferi to cultured endothelial and brain cells. Infect Immun 1998; 66: 994-999.

31. Jackson RL, Busch SJ, Cardin AD. Glycosaminoglycans: molecular properties, protein interactions, and role in physiological processes. Physiol Rev 1991; 71: 481-539.

32. Isaacs RD. Borrelia burgdorferi bind to epithelial cell proteoglycans. J Clin Invest 1994; 93: 809-819.

33. Noel GJ, Love DC, Mossr DM. High-molecular-weight proteins of nontypeable Haemophilus influenzae mediate bacterial adhesion to cellular proteoglycans. Infect Immun 1994; 62: 4028-4033.

34. Cheng P-W, Boat TF, Cranfill K, Yankaskas JR, Boucher RC. Increased sulfation of glycoconjugates by cultured nasal epithelial cells from patients with cystic fibrosis. $J$ Clin Invest 1989; 84: 68-72.

35. Barghouthi S, Guerdoud LM, Speert DP. Inhibition by dextran of Pseudomonas aeruginosa adherence to epithelial cells. Am J Respir Crit Care Med 1996; 154: 1788-1793.

36. de Vries FP, Cole R, Dankert J, Frosch M, van Putten JPM Neisseria meningitidis producing the Opc adhesin binds epithelial cell proteoglycan receptors. Mol Microbiol 1998; 27: $1203-1212$.

37. van Putten JPM, Paul SM. Binding of syndecan-like cell surface proteoglycan receptors is required for Neisseria gonorrhoeae entry into human mucosal cells. EMBO J 1995; 14: 2144-2154.

38. Dehio C, Freissler E, Lanz C, Gómez-Duarte OG, David G, Meyer TF. Ligation of cell surface heparan sulfate proteoglycans by antibody-coated beads stimulates phagocytic uptake into epithelial cells: a model for cellular invasion by Neisseria gonorrhoeae. Exp Cell Res 1998; 242: 528-539.

39. Duensing TD, van Putten JPM. Vitronectin mediates internalization of Neisseria gonorrhoeae by Chinese hamster ovary cells. Infect Immun 1997; 65: 964-970.

40. Ruoslahti E, Yamaguchi Y. Proteoglycans as modulators of growth factor activities. Cell 1991; 64: 867-869. 